\title{
Method and Technique of Life Events Research in Depression and Anxiety
}

\author{
T.I. Oei
}

\begin{abstract}
Methodological aspects still have a decisive impact on the putative etiological role of life events in clinical research. Questions of a diagnostic nature also serve to complicate this kind of research still further, in this present review in particular, when it deals with depression and/or anxiety. The relationship between life events and disturbed behavior also depends on additional variables, such as personality factors and social support. It is for this reason that detailed specification of the concepts used in life events research would seem to be necessary. And finally-when more than two variables are present - the simultaneous application of a number of statistical models is worthy of recommendation.

- 1988 by Grune \& Stratton. Inc.
\end{abstract}

DAYKEL ET AL.'S ${ }^{1}$ pioneer work has provided empirical evidence for the fact that life events (events which affect an individual's life to a significant degree) are important in the development of depression. Or to put it more bluntly: life events can, in fact, actually provoke depressions. ${ }^{2}$ The real meaning of "life-changing" events for an individual, such as the death of a loved one and the ensuing process of mourning, was postulated by Freud as long ago as 1917 and has since become clinically accepted. Although Freud ${ }^{3}$ spoke of melancholia, it is assumed that he was, in fact, primarily concerned with a disturbed mourning process resulting, in consequence, in a clinical depression.

In this review, we will discuss method and technique for life events research, insofar as they are relevant for the clinical researcher. Various aspects will be illustrated on the basis of studies already carried out in the field of depression and anxiety symptoms. Because the area we are dealing with is so comprehensive, we have restricted ourselves to those aspects we feel to be the most important.

\section{THE OPERATIONALIZATION OF LIFE EVENTS}

Life events were first subjected to systematic operationalization by Holmes and Rahe. ${ }^{4}$ They based their method on the concept of change, for them one of the most significant aspects of life events. Moving creates a change in people's feelings of where they belong and their relationship to those around them (neighbors, tradespersons, family, colleagues, etc.). The level of adaptation received their primary attention. How quickly does one come to terms with changes in one's life pattern? How flexible is one's mental attitude towards one's environment?

Paykel's group, 1,5 extended Holmes and Rahe's Readjustment Schedule by including divisions covering different kinds of life events. They made a distinction not only between desired and undesired life events, but also laid special emphasis on

From the Department of Ambulatory and Social Psychiatry, Academic Hospital, Utrecht, The Netherlands.

Address reprint requests to T.I. Oei, M.D., Ph.D., F.C.C.P., Senior Lecturer, Department of Ambulatory and Social Psychiatry. Academic Hospital, Catharijnesingel 101, 3511 GV Utrecht, The Netherlands.

(c) 1988 by Grune \& Stratton, Inc.

$0010-440 X / 2906-0006 \$ 03.00 / 0$ 
exits (those events involving a loss of one's social environment, e.g., following the death of a partner) and entrances (events which add positively to one's social environment, e.g., the birth of a child in the family). In addition, Paykel et al., ${ }^{6}$ introduced the concept of impact-how intensely is a person's life influenced by life events? They subdivided this element into subjective impact (influential life events as reported by the patient) and objective impact (how the "average" person experiences particular life events), and was in this way able to answer the need for a contextual aspect of life events. Life events do not occur in a vacuum. They are most often the products of action-reaction and interaction, and are restricted in time. If we take, for instance, the death of a respondent's partner as a result of a brain tumor, we see that at Time I (TI) the existence of the tumor becomes manifest in the form, for instance, of headaches, nausea and vomitting, etc. From the moment the diagnosis is known until the actual and unavoidable separation (TII), the respondent has to live through a period of deep uncertainty. Brown's group ${ }^{7,8}$ called this threatening process contextual threat. Paykel's objective negative impact was really a modification of Brown's contextual threat. In the absence of further clarification and application, in practice, of concepts such as impact and contextual threat, the level at which life events are actually experienced will remain insufficiently understood.

\section{MEASURING LIFE EVENTS}

Holmes and Rahe 4 use a method of assessing life events according to "weight" (e.g., the loss of the spouse 100, marriage 50). The more a person is subjected to "heavy-weight" life events, the greater the chance of their developing at a later stage some form of behavioral disturbance. The list was intended for self-reporting. Researchers have tended for some time now to direct their efforts to the systematic recollection of life events. ${ }^{9-11}$ And the question has usually been: what is the most appropriate method for research purposes, the questionnaire or the interview? Other researchers have shown a strong preference for the questionnaire. This, they felt, offered more capacity for the respondent because he or she is free to determine what is important and what is not. There is no external control and no extra pressure from outside, in preparing as accurate an answer as possible to the questions asked. The questionnaire also has the advantage of being completed in the trusted and relaxed atmosphere of the home situation, and the chances of being influenced by a third party, therefore, are kept to a minimum. On the whole, the time needed for self-reporting is significantly shorter than for the interview method. ${ }^{2}$ Although the respondent is requested to complete the questionnaire in full, the possibility remains that he or she may make his or her own variation by "ignoring" or "forgetting" items of "too personal" a nature. In connection with the tendency to understand certain events from the personal situation, the reporting can also lead to falsepositive scores, in addition to a tendency to report more events than have actually occurred, i.e., "effort after meaning." 13 An extra hazard is the frequent occurrence of a "memory narrowing," i.e., patients "rcmember" events as having taken place at a time closer to the onset of the illness than was in fact the case ("telescope effect" ${ }^{\prime 14}$ ).

Therefore, there is all the more reason when the questionnaire technique is used, for the researcher to take the time-after the written reporting procedure-to go through all the questions in detail with each respondent. ${ }^{12,15,16}$ The chance that 
events can often be more the cause than the effect of the disorder under investigation (e.g., dismissal from one's work because of depression, instead of vice versa) has led to the conviction that the interview method, seen as a whole, is more "sensitive" than the questionnaire.,11,12,17,18 The interview possesses an extra safeguard in that in addition to, albeit carefully formulated, written questions, the researcher, in his or her quest for greater accuracy, can "probe" further by reformulating and retiming the questions to which the answers are still unclear. Zimmerman advises researchers who "collect life event information by interview rather than paper and pencil self-report inventories, [that] they must be careful to expose both the controls and the patients to the same type of intensive and probing format." 19 The interview technique in the so-called semistructured form, is also to be recommended above the totally standardized interview because it guarantees more precise reporting. ${ }^{20}$

\section{WHAT IS THE RESEARCHER'S THEORETICAL STARTING POINT?}

Life events and disturbed behavior do not solely interact, but are always influenced, in one way or another, by additional variables, such as "social support." This conviction resulted in the formulation of at least four working hypotheses. ${ }^{21}$

\section{The Vulnerability Hypothesis}

The additional variable increases the psychological distress when life-stress is also present, but has, on the other hand, no effect at all when life-stress is absent.

\section{The Mutual Potentiation Hypothesis}

The additional variable increases the level of psychological distress only when combined with a high degree of life-stress. When one of these two factors-either the additional variable or the life-stress-is of such minor significance in a individual's life situation, then the psychological distress will also remain at a low level.

\section{The Independent Causes Hypothesis}

The extent to which the additional variable increases the level of psychological distress is quite independent of the degree of life-stress.

\section{The Synergism Hypothesis}

The additional variable and life-stress, each representing independently a particular psychological distress, and whilst interlinked they exercise a disproportionate influence on the growing level of psychological distress.

Katschnig ${ }^{18}$ has suggested a taxonomy of four different measurement levels to determine the stressfulness of a single life event within a hierarchical relationship:

Level 1: All life events are regarded as being equally stressful.

Level 2: Different weights are given to different types of life events.

Level 3: The context of the event must be taken into account.

Level 4: Subjectively experienced life-stress.

In principle, every researcher can combine one of the work hypotheses mentioned above (Cooke) with one or more of the levels suggested by Katschnig. Brown and Harris, ${ }^{8}$ for instance, have used the vulnerability hypothesis in their studies and have based their life events reporting primarily on Katschnig's third and fourth levels. Andrews et al., ${ }^{22-24}$ on the other hand, have developed a scale according to 
which a different weight is allotted to each different type of life event (Katschnig's second level), whilst basing their interpretations principally on Cooke's independent causes hypothesis.

\section{A NUMBER OF PRACTICAL PROBLEMS IN LIFE EVENTS RESEARCH IN CASES OF DEPRESSION AND ANXIETY DISORDERS}

Paykel $^{25}$ suggests quite rightly that researchers often by-pass the definition of what a "life event" really is. He describes a life event as "a discrete change in the subject's social or personal environment." He means, in this context, a change explicitly verifiable by the world outside and includes in this the physical sickness which can be subjected to objectivity and can also initiate changes in both the social milieu and in the individual's own life pattern.

One of the hazards of life events research in cases of depression, concerns the diagnostic aspect. The problem can roughly be divided into two areas:

\section{The Contamination of Life Event Scales by the Use of Symptom-Like Items (i.e., "Change in Eating Habits")}

The Schedule of Recent Experience (SRE) compiled by Holmes and Rahe, ${ }^{4}$ in particular, has been the target of considerable criticism. Hudgens, ${ }^{26}$ for instance, was able to identify 29 out of the 43 items on the Holmes and Rahe scale as being symptoms rather than causes of the disorder. This means that the use of the SRE blocks the way to attributing any kind of etiological significance to life events.

\section{The Actual Diagnostics}

The introduction of depression scales directed towards recognizing depressive behavior, has not in any way silenced the ongoing debates over the actual onset of depression. Although it was originally thought that a dichotomy existed between "endogenous" and "reactive" depression, ${ }^{27}$ later work leant more towards the idea of various forms of one kind of depression. ${ }^{28,29}$ Some workers even suggested three or four subgroups of depression. ${ }^{30,31}$ The ICD- $9^{32}$ and the DSM-III ${ }^{33}$ and the DMSIII-R, ${ }^{34}$ respectively, each base their classifications on the classical depression dichotomy. From the practical point of view, one might well ask: what exactly is the difference between patients with clinically diagnosed types of depression and people everywhere in society showing depressive symptoms ("emotional distress") without ever being referred to a specialist? This has partly to do with whether or not a General Practitioner (GP) readily refers his or her patients to hospital specialists. What in one area is considered treatable by one's own GP (sometimes not even being called depression), is in another area regarded as worthy of referral to a psychiatric outpatient department..$^{35}$ A number of studies ${ }^{36-39}$ have suggested that depressives, treated by GP's, as a whole have milder, shorter illnesses than psychiatric samples, with depression less endogenous in symptom pattern and more related to recent situational-stress.

Brown et al ${ }^{40,41}$ suggest that the chance in a particular area of more depressed patients registering for outpatient psychiatric treatment, is largely dependent on the manner in which people present their symptoms. Brown attempts hereby to underline the multi-causal onset of depressive behavior. Bebbington, ${ }^{15,42}$ however, using the same (multi-casual) model as his starting point, sees more likelihood of a combination of biological and psychosocial factors as being the cause of depression. 
He also feels that the essential conditions for distinguishing between distress and depression lie primarily in either the symptomatic, or causal (including psychosocial) factors. It is important to bear in mind, of course, that a different group of symptoms separates (clinical) depression from emotional distress. Of vital importance for life-events research as an etiological paradigm, is the relationship between distress and/or depression with a psychosocial background.

In the case of anxiety disturbances, the amount of (life events) research has been almost negligible and the reasons must be sought principally in the area of diagnostics. Anxiety is an important human phenomenon, and its presence is regularly felt in the symptom complex common to depressions. Paykel ${ }^{31}$ speaks of an anxious-depressive subtype. Others, such as Roth et al., ${ }^{43}$ typify anxiety as a separate syndrome. Finlay-Jones et al. ${ }^{44}$ also make a distinction between anxiety as an isolated entity and cases in which anxiety and depression are combincd (or separate) in one person. Finlay-Jones and Brown ${ }^{45}$ presented evidence for the need to distinguish between depression and anxiety, also from the point of view of experienced life-events: it became apparent, for instance, that severe loss was a causal factor of the onset of a depression, while serious danger proved capable of provoking anxiety disturbances. In the case of the combination depression/anxiety, the chance is high that patients will report both severe loss and serious danger. Roy-Byrne et al. ${ }^{46}$ came to the same conclusion and their preliminary data suggest that the occurrence of a major loss (e.g., death of a loved one) in patients with panic disorder may confer an increased risk for a subsequent "secondary" depression. Faravelli ${ }^{47}$ found a relationship between life events and the onset of (DSM-III) panic disorder. Special loss events and threatening events play an undoubted role as symptom provokers.

Clearly, there is a great deal of uncharted territory in the field of life-events research with patients trying to cope with various forms of depression and anxiety, and for whom controlled scientific study is still lacking. One of the problems is, how can we apply the distinction depression/anxiety and for which purpose? Grayson et al., ${ }^{48}$ for example, established that anxiety and depression are very probably distinct and substantially correlated illnesses. But notwithstanding this view, they support like Barlow et al., ${ }^{49}$ the idea that, for etiological research, the illnesses could probably be better measured dimensionally than by imposing hierarchical dichotomies. However, although ID-Catego, ${ }^{50}$ Bedford College, ${ }^{44}$ and DSM-III, emerge as reliable indicators of psychiatric disorder, with anxiety, the construct validity is suspect with DSM-III and ID-Catego. ${ }^{48}$

The main obstacles (in life-events research) lie at present not only in the area of diagnostics but more especially in the field of methodology. On which disorder are we going to concentrate and with which life-event instrument are we tending to study which period of time? This latter aspect often gives rise to misunderstandings and errors. Two of the most burning issues are:

1. The index period over which life events have to be retraced could be as short as 6 to 12 months before the onset of the disorder (i.e., mostly depression) but certainly not longer than 2 years. This takes account of the $3 \%$ per month average "fall-off" in the ability to recall. ${ }^{25}$

2. The degree of "independence" inherent in any given event. ${ }^{7}$ This points to the fact that an event can have two aspects, as often becomes apparent in the course of the researcher's "probing" of the respondent for more detail: it can, on the one hand, 
be the cause of a disorder ("independent") and, on the other hand, can also be the effect of a disorder ("dependent").

Loss of employment because the company has gone bankrupt is a very different experience from that of being dismissed following a long period of sick-leave and inability to function adequately (e.g., because of chronic depression).

\section{SOME SUGGESTIONS FOR FUTURE STUDY IN LIFE EVENTS RESEARCH}

We would like finally to propose two essential topics for possible future research in the field of life-events.

The first topic concerns the statistical analysis of the data. A long time has passed since life-events research concentrated solely on the direct relationship between life-event(s) and disorder. The field is, of course, much wider and everyone understands the complexity of the problem. We will always have to concern ourselves with the interaction between certain variables-whether or not they affect the respondent personally in sociodemographic terms or from the point of view of social support-and one (or more) "protagonists" in the association between life-events and disturbed behavior. One of the main problems is the (possible) interaction between the "provoking agent" and the "vulnerability factor." Brown and Harris" have shown that women, on the basis of a vulnerability factor (death of the mother before the age of 11 years, three or more children in the family all under 14 years of age, longstanding unemployment, the absence of a permanent relationship), run the risk of becoming depressive in the aftermath of some form of severe event ("provoking agent" or "major difficulty"). For Tennant and Bebbington," however, the chain is more complicated: if "stress" is presumed to be a provoking agent or a vulnerability factor, then it must also be assumed that a higher risk of developing depression is inherent in each separate variable. They substantiate their view by applying the log-linear statistics, in contrast to the additive model used by Brown and Harris ${ }^{8}$ who came to the conclusion that the Tennant and Bebbington method was not really relevant. ${ }^{52,53}$ Brown ${ }^{54}$ takes the view that variables as a whole (provoking agent, major difficulty, vulnerability factor) are not hierarchically connected, because it is not yet clear how and in what way the factors mentioned can be regarded as potentially depressogenic. For the time being, therefore, they will have to be approached in isolation from each other. Everitt and Smith, ${ }^{55}$ when discussing these matters, concluded that it would probably be better to apply several methods of data analysis simultaneously.

The second topic concerns the adequate analysis of research data with regard to: (a) the totality of the concepts applied; and (b) the specificity of the accepted concepts.

In one of Harris and Brown's ${ }^{56}$ most interesting articles, scientific information of a high caliber is presented in an effort to show how ambiguities in the reporting of research data can lead to serious misunderstandings. One of the examples given concerns the loss of a parent in childhood; loss can be interpreted as "death" or "permanent or temporary separation." Total application of this concept would seem to be important and "it would have been helpful if these [trends in each subgroup] had been given, as well as the aggregated figures." 56

The concept of social support can have several meanings and includes structural and functional aspects. ${ }^{57}$ Membership in a hobby club is a fact quite different from 
the capacity to be self-asserting. The perception of social support is also open to individual interpretation. ${ }^{58}$ Not everyone feels helped because the neighbor makes no noise. It appears from a study carried out by Brown and Bifulco, ${ }^{59}$ that if a woman is married, but is deprived of any form of intimate contact with her husband, every other form of support, however intensive in itself, can provide only partial compensation for what the marriage lacks. Intimacy, it seems, belongs to the vulnerability factor. ${ }^{59}$

In conclusion, we see that life-events research has progressed from the inventarisation level ${ }^{4}$ to the connection-perspective level. ${ }^{1,6,7}$ At this level, concepts bearing a contextual meaning, such as "impact," "contextual threat," "desired," "undesired," "independent," and "dependent," have the upper hand. The relationship between life events and disturbed behavior is complicated furthermore by the presence of additional variables, such as personality attributes and social support. There is an urgent need for the concepts in their totality, as well as their specificity, to be clarified. There is still a long way to go before the diagnostic aspects of depression and anxiety disorders have been fully investigated and understood. The (simultaneous) application of several statistical models-in the presence of distributions of at least three variables-is perhaps worthy of serious consideration. In this way, we might ultimately hope to obtain concrete corroboration for the scientific validity of our methodology.

\section{ACKNOWLEDGEMENT}

The help given by Sylvia Dierks-Mallett in the preparation of this paper is gratefully acknowledged.

\section{REFERENCES}

1. Paykel ES, Myers JK, Dienelt MN, et al: Life events and depression. A controlled study. Arch Gen Psychiatry 21:753-760, 1969

2. Lloyd C: Life events and depressive disorder reviewed. II. Events as precipitating factors. Arch Gen Psychiatry 37:541-548, 1980

3. Freud S: Mourning and Melancholia. Standard Edition 18. London, Hogarth, 1955, pp 7-67

4. Holmes TH, Rahe RH: The social readjustment rating scale. J Psychosom Res 11:213-218, 1967

5. Paykel ES: Recent life events and clinical depression, in Gunderson EK, Rahe RH (eds): Life Stress and Illness. Springfield, IL, Thomas, 1974, 134-163

6. Paykel ES, Emms EM, Fletcher J, et al: Life events and social support in puerperal depression. Br J Psychiatry 136:339-346, 1980

7. Brown GW, Sklair F, Harris TO, et al: Life-events and psychiatric disorders. Part I: Some methodological issues. Psychol Med 3:74-87, 1973

8. Brown GW, Harris T: The Social Origins of Depression: A Study of Psychiatric Disorder in Women. London, Tavistock, 1978

9. Bebbington P, Tennant C, Sturt E, et al: The domain of life events: A comparison of two techniques of description. Psychol Med 14:219-222, 1984

10. Brown GW: Meaning, measurement and stress of life events, in Dohrenwend BS, Dohrenwend BP (eds): Stressful Life Events: Their Nature and Effects. New York, Wiley, 1974, pp 217-243

11. Paykel ES: Methodological aspects of life events research. J Psychosom Res 27:341-352, 1983

12. Oei TI, Zwart FM: The assessment of life events-self-administered questionnaire versus interview. J Affect Disord 10:185-190, 1986

13. Bartlett FC: Remembering-A Study of Experimental and Social Psychology. London, Cambridge University Press, 1932

14. Day R, Nielsen JA, Korten A, et al: Stressful life events preceding the acute onset of schizophrenia: A cross-national study from the World Health Organization. Cult Med Psychiatry $11: 123-205,1987$ 
15. Bebbington P: Establishing causal links-recent controversies, in Katschnig H (ed): Life Events and Psychiatric Disorders: Controversial Issues. London, Cambridge University Press, 1986, pp $188-200$

16. Oei TI, Zwart FM: Life events in dermatological and depressive inpatients. New Trends Exper Clin Psychiatry 33:157-164, 1987

17. Katschnig H: Measuring Life Stress: A Comparison of Two Methods. Farmer R, Hirsch S (eds). London, Croom Helm, 1980, pp 116-123

18. Katschnig $\mathrm{H}$ : Measuring life stress-a comparison of the checklist and the panel technique, in Katschnig $\mathbf{H}$ (ed): Life Events and Psychiatric Disorders: Controversial Issues. London, Cambridge University Press, 1986, pp 74-106

19. Zimmerman M: Methodological issues in the assessment of life events: A review of issues and research. Clin Psychol Rev 3:339-370, 1983

20. Paykel ES: Life events, social support and clinical psychiatric disorder, in Sarason IG, Sarason BR (eds): Social support: Theory, research and applications. Dordrecht, Holland, Nijhoff, 1985, pp 321-348

21. Cooke DJ: Psychosocial variables and the life event/anxiety-depression link-A community study. Acta Psychiatr Scand 74:281-291, 1986

22. Tennant C, Andrews G: A scale to measure the stress of life events. Aust N Z J Psychiatry $10: 27-32,1976$

23. Andrews G, Tennant C: Life event stress and psychiatric illness. Psychol Med 8:545-549, 1978

24. Andrews G, Tennant C, Hewson D, et al: Life event stress, social support, coping style and risk of psychological impairment. J Nerv Ment Dis 166:307-316, 1978

25. Paykel ES: Methodology of life events research. Adv Psychosom Med 17:13-29, 1987

26. Hudgens RW: Personal catastrophe and depression. A consideration of the subject with respect to medically ill adolescents, and a requiem for retrospective life-event studies, in Dohrenwend BS, Dohrenwend BP (eds): Stressful Life Events: Their Nature and Effects. New York, Wiley, 1974, pp 119-134

27. Hamilton M, White JM: Clinical syndromes in depressive states. J Ment Sci 105:985-998, 1959

28. Kendell RE: The classification of depressive illnesses. Maudsley Monograph No. 18. London, Oxford University Press, 1968

29. Lindenbergh EDJ: Het symptoom-profiel van de depressieve patient. Meer soorten of meer van één soort? Amsterdam, Rodopi, 1985

30. Overall JE, Hollister LE, Johnson M, et al: Nosology of depression and differential response to drugs. JAMA 195:946-948, 1966

31. Paykel ES: Classification of depressed patients: A cluster analysis derived grouping. $\mathrm{Br} \mathbf{J}$ Psychiatry 118:275-288, 1971

32. World Health Organization. Mental disorders: Glossary and guide to their classification in accordance with the ninth revision of the International Classification of Diseases. Geneva, WHO, 1978

33. American Psychiatric Association. Diagnostic and Statistical Manual of Mental Disorders, 3rd edition, (DSM-III). Washington, D.C., American Psychiatric Association, 1980

34. American Psychiatric Association. Diagnostic and Statistical Manual of Mental Disorders, 3rd edition, revised. Washington, D.C., $\Lambda$ merican Psychiatric Association, 1987

35. Goldberg DP, Huxley P: Mental illness in the community. London, Tavistock, 1980

36. Fahy TJ: Pathways of specialist referral of depressed patients from general practice. $\mathrm{Br} \mathbf{J}$ Psychiatry 124:231-239, 1974

37. Johnson DAW, Mellor V: The severity of depression in patients treated in general practice. J R Coll Gen Pract 27:419-422, 1977

38. Sireling L, Freeling P, Paykel ES, et al: Depression in general practice: Case thresholds and diagnosis. Br J Psychiatry 147:113-119, 1985

39. Sireling LI, Freeling P, Paykel ES, et al: Depression in general practice: Clinical features and comparison with outpatients. Br J Psychiatry 147:119-126, 1985

40. Brown GW, Craig TKJ, Harris TO: Depression: Distress or disease? Some epidemiological considerations. Br J Psychiatry 147:612-622, 1985

41. Brown GW, Craig TKJ: Psychiatric cases in community studies: How important an issue? Soc Sci Med 22:173-183, 1986

42. Bebbington P: Misery and beyond: The pursuit of disease theories of depression. Int $J$ Soc Psychiatry 33:13-20, 1987 
43. Roth M, Gurney C, Garside RF, et al: Studies in the classification of affective disorders: The relationship between anxiety states and depressive illnesses: $\mathrm{I}$. Br J Psychiatry 121:147-161, 1972

44. Finlay-Jones R, Brown GW, Duncan-Jones P, et al: Depression and anxiety in the community: Replicating the diagnosis of a case. Psychol Med 10:445-454, 1980

45. Finlay-Jones R, Brown GW: Types of stressful life event and the onset of anxiety and depressive disorders. Psychol Med 11:803-815, 1981

46. Roy-Byrne PP, Geraci M, Uhde TW: Life events and course of illness in patients with panic disorder. Am J Psychiatry 143:1033-1035, 1986

47. Faravelli C: Life events preceding the onset of panic disorder. J Affective Disord 9:103-105, 1985

48. Grayson DA, Bridges $K$, Duncan-Jones $P$, et al: The relationship between symptoms and diagnoses of minor psychiatric disorder in general practice. Psychol Med 17:933-942, 1987

49. Barlow DH, DiNardo PA, Vermilyea BB, et al: Co-morbidity and depression among the anxiety disorders. J Nerv Ment Dis 174:63-72, 1986

50. Wing JK, Sturt E: The PSE-ID-CATEGO System Supplementary Manual. London, MRC Social Psychiatry Unit, Institute of Psychiatry, 1978

51. Tennant $C$, Bebbington P: The social causation of depression: A critique of the work of Brown and his colleagues. Psychol Med 8:565-575, 1978

52. Brown GW, Harris T: Social origins of depression-A reply. Psychol Med 8:577-588, 1978

53. Brown GW, Harris T: Establishing causal links: The Bedford College studies of depression, in Katschnig H (ed): Life Events and Psychiatric Disorders: Controversial Issues. London, Cambridge University Press, London, 1986, pp 107-187

54. Brown GW: Statistical interaction and the role of social factors in the aetiology of clinical depression. Sociology 20:135-140, 1986

55. Everitt BS, Smith AMR: Interactions in contingency tables: $A$ brief discussion of alternative definitions. Psychol Med 9:581-583, 1979

56. Harris T, Brown GW: Interpreting data in aetiological studies of affective disorder: some pitfalls and ambiguities. Br J Psychiatry 147:5-15, 1985

57. Oei TI: Psychic coping behaviour and the role of Social Support. Int J Soc Psychiatry 33:5-12, 1987

58. Oei TI: Life events (2)-De betekenis van sociale steun in theorie en praktijk. Soma Psyche Wereldwijd 13:8-10, 1987

59. Brown GW, Bifulco A: Social support, life events and depression, in Sarason IG, Sarason BR (eds): Social Support: Theory, Research and Applications. Dordrecht, Holland, Nijhoff, 1985, pp 349-370 